\section{(6) OPEN ACCESS}

\title{
Novel approach for independent control of brain hypothermia and systemic normothermia: cerebral selective deep hypothermia for refractory cardiac arrest
}

\author{
Chih-Hsien Wang, ${ }^{1}$ Yu-Ting Lin, ${ }^{1}$ Heng-Wen Chou, ${ }^{1}$ Yi-Chih Wang, ${ }^{1}$ \\ Joey-Jen Hwang, ${ }^{1}$ John R Gilbert, ${ }^{2}$ Yih-Sharng Chen ${ }^{1}$
}

\begin{abstract}
${ }^{1}$ Department of Cardiovascular Surgery, National Taiwan University Hospital, Taipei, Taiwan

${ }^{2}$ Asia Pacific Medical Technology Development Company, Hong Kong, China
\end{abstract}

\section{Correspondence to}

Professor Y-S Chen

Department of Cardiovascular

Surgery, National Taiwan

University Hospital,

7 Chung-Shan S Rd

Taipei 100, Taiwan;

yschen1234@gmail.com,

yschen11@mail2000.com.tw

Accepted 7 December 2016

\section{CrossMark}

\footnotetext{
To cite: Wang C-H, Lin Y-T, Chou H-W, et al. BMJ Case Rep Published online: [please include Day Month Year] doi:10.1136/bcr-2016012806
}

\section{SUMMARY}

A 38-year-old man was found unconscious, alone in the driver's seat of his car. The emergency medical team identified his condition as pulseless ventricular tachycardia. Defibrillation was attempted but failed. Extracorporeal membrane oxygenation (ECMO) was started in the emergency room 52 min after the estimated arrest following the extracorporeal cardiopulmonary resuscitation (ECPR) protocol in our center. The initial prognosis under the standard protocol was $<25 \%$ chance of survival. A novel adjunctive to our ECPR protocol, cerebral selective deep $\left(<30^{\circ} \mathrm{C}\right)$ hypothermia (CSDH), was applied. CSDH adds a second independent femoral access extracorporeal circuit, perfusing cold blood into the patient's common carotid artery. The ECMO and CSDH circuits demonstrated independent control of cerebral and core temperatures. Nasal temperature was lowered to below $30^{\circ} \mathrm{C}$ for 12 hours while core was maintained at normothermia. The patient was discharged without significant neurological deficit 32 days after the initial arrest.

\section{BACKGROUND}

Extracorporeal cardiopulmonary resuscitation (ECPR) has become a useful approach in treating adult refractory cardiac arrest patients. The ECPR protocol implemented at our center ${ }^{1}$ has shown improved survival and neurological outcomes. ${ }^{2}{ }^{3}$ Following refractory arrest, when the patient arrives at the emergency room (ER), the ECPR protocol involves application of extracorporeal membrane oxygenation (ECMO) to end their period of low flow ischemia. The ECMO circuit is then used to support recovery of cardiac output over a period of several days before a controlled weaning process is initiated. Currently, systemic therapeutic hypothermia at $33-35^{\circ} \mathrm{C}$ is a complementary neuroprotection strategy used at our center, applied to the subset of ECPR patients with a Glasgow Coma Scale (GCS) score of $<6$, as evaluated following ECMO initiation. This procedure is within the current ILCOR guidelines, ${ }^{4}$ although the guidelines have no specific recommendation for ECPR refractory arrest patients.

Any improved neuroprotection approach would be valuable in refractory cardiac arrest patients and possibly in other patients with ischemic injury. The investigators had two motivations in the design of the cerebral selective deep $\left(<30^{\circ} \mathrm{C}\right)$ hypothermia (CSDH) protocol: (1) to enable therapeutic hypothermia to be applied to the cerebral region without negative side effects on the core; (2) to enable application of temperatures below $30^{\circ} \mathrm{C}$ in ECPR, following two studies of selective hypothermia below $30^{\circ} \mathrm{C}$ in surgical animal stroke models. ${ }^{5}$

In the present case, implementation of the $\mathrm{CSDH}$ protocol demonstrated that it is feasible to establish prolonged ( $>12$ hours) separate temperature controlled zones for the core and cerebral regions. Hence it may be a feasible procedure to allow potential neuroprotective hypothermia to be applied to the brain while not incurring the negative effects of hypothermic temperatures on core organ systems. We do not believe or assert that the case demonstrates efficacy or clinical value, even though the specific outcome was favorable. Evaluation of the efficacy of the CSDH protocol and choice of target temperatures will require larger studies.

\section{CASE PRESENTATION}

A bystander found a 38-year-old man unconscious, alone in the driver's seat. No cardiopulmonary resuscitation (CPR) was performed before arrival of the emergency medical team (EMT). The EMT recorded an initial rhythm of pulseless ventricular tachycardia. Several attempts at defibrillation were made but failed. The patient was transferred to the hospital ER under continuous manual CPR. Initial laboratory reports in the ER showed a $\mathrm{pH}$ of 7.03 and lactate value of 6.31 . The patient was deemed appropriate for ECPR, and ECMO was set up according to our previous protocols. ${ }^{1}$ ECMO was started 52 min after the estimated arrest. At that time, the patient had at least $8 \mathrm{~min}$ of no flow followed by $44 \mathrm{~min}$ of manual CPR after arrival of the EMT. Neurological re-evaluation after ECMO initiation gave a GCS score of 4-5 with intubation (eye, E1; motor, M3-4).

Based on our prior experience, including 230 adult ECPR cases, ${ }^{7}$ a prognosis was constructed based on out-of-hospital cardiac arrest, age, GCS score, initial rhythm, and period of no flow and low flow before the start of ECMO. For similar patients, the prognosis for survival is $22-25 \%$, and the prognosis for a good neurological recovery is 
lower. The patient was expected to have an unfavorable clinical outcome.

\section{INVESTIGATIONS}

Based on the prognosis, the medical team offered the patient's family the option of applying the investigational CSDH protocol as an adjunct to our center's standard ECPR protocol. All of the hospital's standard institutional review board emergency approval procedures were followed for the case reported here.

\section{TREATMENT}

The CSDH protocol was applied as an adjunct to the standard ECPR protocol by adding a second independent extracorporeal circuit, as shown in figure 1. The first circuit was inserted in the ER for standard ECMO/ECPR, and the second was inserted through the opposite leg, implementing CSDH. Each extracorporeal circuit has an independent heat exchange system, allowing independent temperature control. The time course and strategy of the underlying ECPR protocol is not changed by CSDH, and the CSDH circuit can be established and removed without disruption of the ECPR protocol. The cannula for the CSDH circuit is a $14 \mathrm{~F}$ concentric lumen catheter (TwinFlo; ThermopeutiX, San Diego, USA). The TwinFlo catheter is inserted through a single puncture in the left femoral artery and its outer lumen is placed in the aortic arch, while its inner lumen is advanced into the right internal carotid artery (figure 2).

Systemic hypothermia was started in the intensive care unit using the ECMO circuit heat exchange system. The initial systemic target temperature was $34^{\circ} \mathrm{C}$, as measured with a bladder temperature probe.

After the consent process, the patient was sent to the catheterization laboratory to set up the CSDH circuit in the right carotid artery. Angiography was performed to confirm the patency of the coronary artery and absence of carotid stenosis. After insertion of the CSDH circuit, the patient was sent back to the intensive care unit for $\mathrm{CSDH}$ cooling initiation and operation.

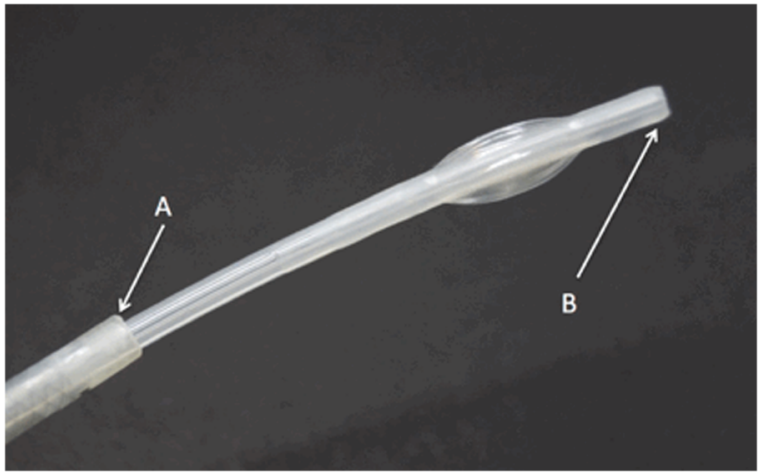

Figure 2 The TwinFlo catheter used in the cerebral selective deep hypothermia protocol. The outer lumen opening $(A)$ is placed into the aortic arch and core temperature blood is removed through the outer lumen. The distal tip of the inner lumen (B) is advanced into the internal carotid and cooled blood is injected there.

The patient's temperature was monitored using probes at the bladder, right (ipsilateral to the cooling catheter tip) nasal, and left nasal locations. At the start of systemic hypothermia, the ECMO circuit heat exchanger is initially set to maintain bladder temperature at $34^{\circ} \mathrm{C}$.

The CSDH protocol was designed to cool to the target temperature and to hold that temperature for 12 hours, followed by gradual rewarming at $0.5^{\circ} \mathrm{C} /$ hour. The target temperature was a right nasal temperature of $27 \pm 3^{\circ} \mathrm{C}$. The flow in the $\mathrm{CSDH}$ circuit was kept between 200 and $250 \mathrm{~mL} / \mathrm{min}$ during the procedure, as needed. Figure 3 shows the observed temperature profiles during the CSDH part of the procedure. While CSDH was operating, the ECMO circuit was used to maintain core (bladder) temperature in a normothermic range. During $\mathrm{CSDH}$, the right and left nasal probes were within $1.5 \pm 0.58^{\circ} \mathrm{C}$ of each other.

$\mathrm{CSDH}$ cooling started at hour 13, target temperature was reached at hour 15 , rewarming started at hour 29 , and rewarming ended and the CSDH circuit was withdrawn at hour 51.
Figure 1 Schematic diagram of the protocol. The extracorporeal membrane oxygenation-cerebral selective deep hypothermia (ECMO-CSDH) protocol uses two independent extracorporeal circuits: the one for standard ECMO is established using a cut-down in the emergency room and continues for $3-5$ days; the other is established by a single standard femoral percutaneous puncture for placement of the TwinFlo cannula. CSDH circuit inserts, operates, and may be removed independently of the ECMO circuit.

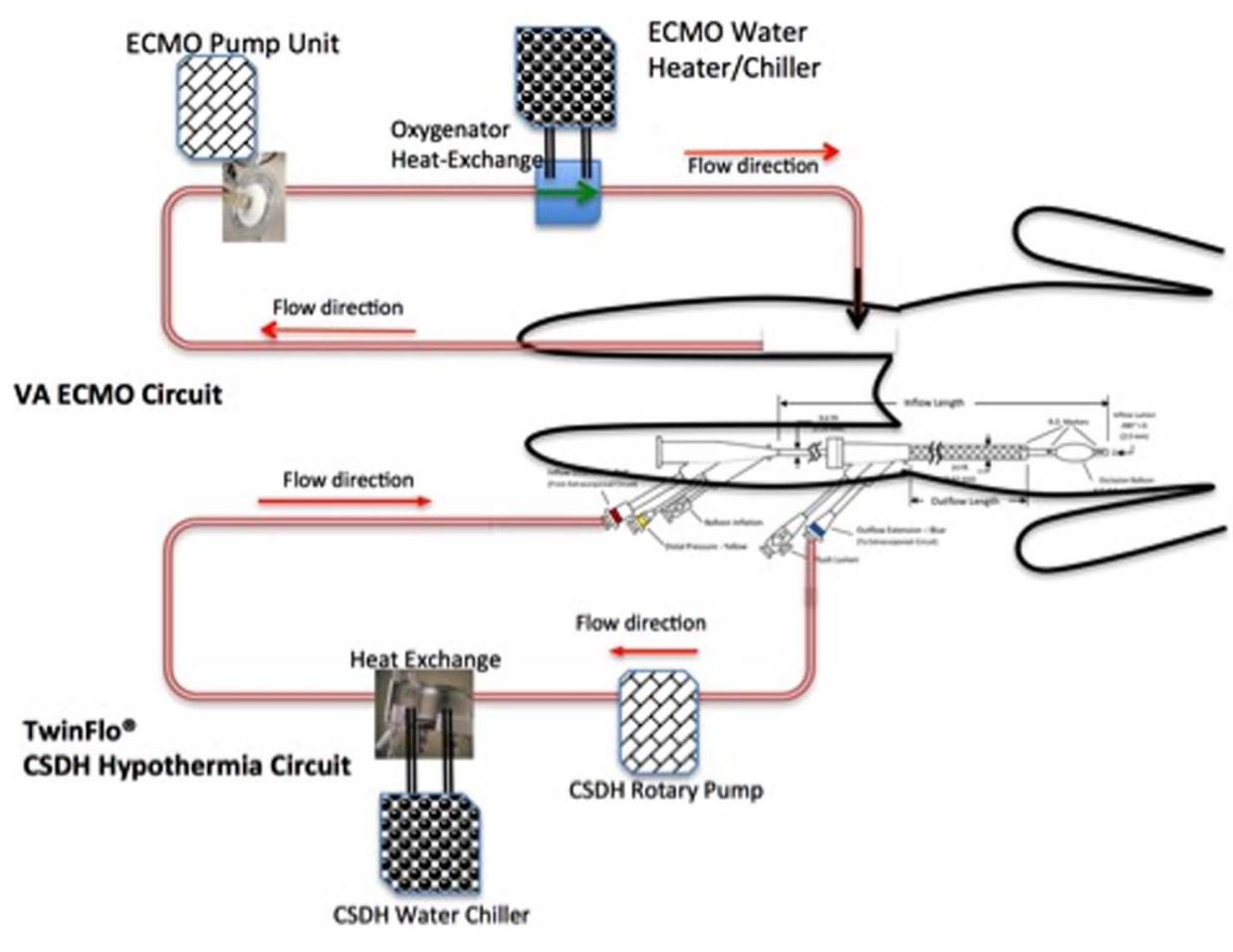

Wang C-H, et al. BMJ Case Rep 2017. doi:10.1136/bcr-2016-012806 


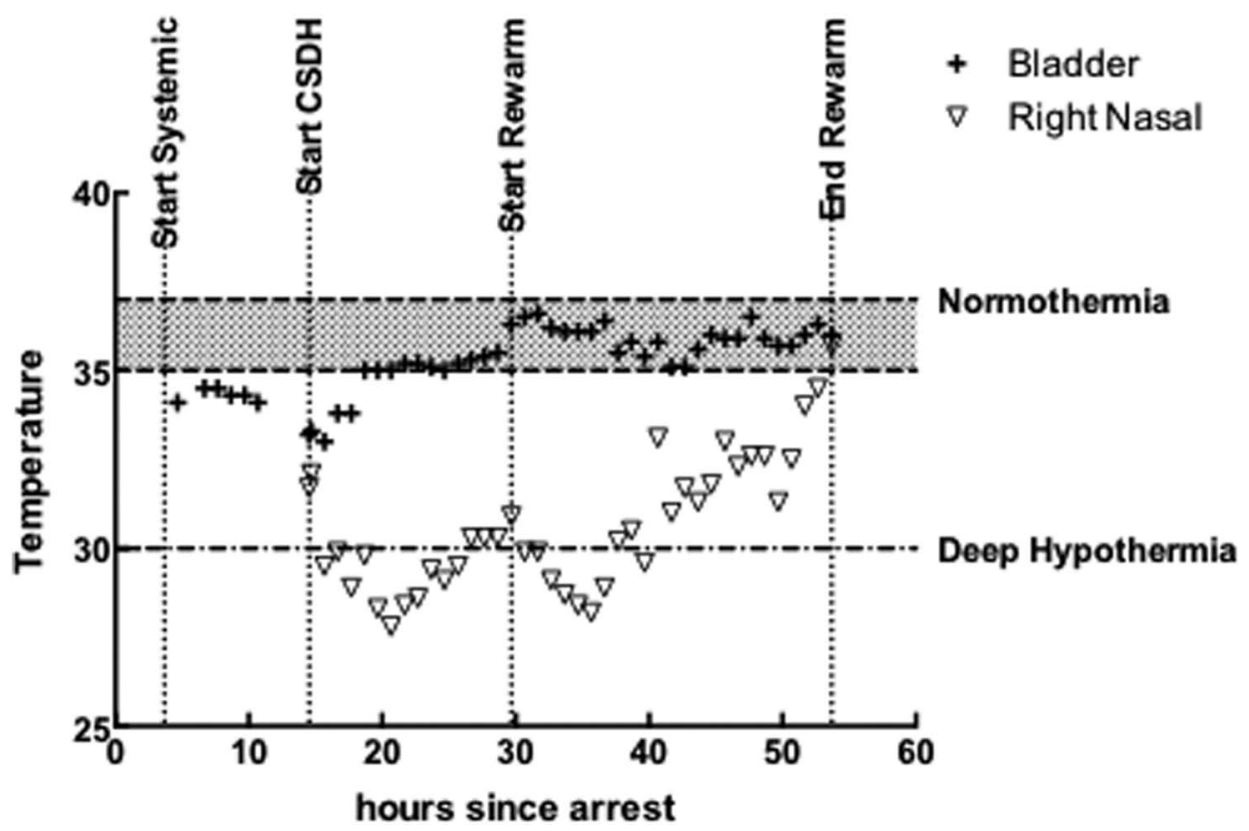

Figure 3 Temperature versus time from estimated arrest. The extracorporeal membrane oxygenation (ECM0) circuit flow started 52 min from arrest, systemic hypothermia via the ECMO circuit started at 3.7 hours, and cerebral selective deep hypothermia (CSDH) circuit cooling started at 13.7 hours and reached the target band for ipsilateral nasal temperature (right) $\left(27 \pm 2^{\circ} \mathrm{C}\right)$ at 17.7 hours. The CSDH temperature was held for 12 hours until hour 29.7 and then gradual rewarming was implemented for $\sim 24$ hours. Following the rewarming period, the CSDH circuit was shut down and removed, although the ECMO operation continued to support flow until ECMO weaning on day 3 . The patient received 11 hours of cerebral temperature below $30^{\circ} \mathrm{C}$ (based on right nasal temperature), and over the period from initial achievement of the target temperature to the start of rewarming, the difference between the right nasal temperature and the core temperature was $5.6 \pm 0.9^{\circ} \mathrm{C}$.

Following the center's standard ECPR protocol, activated clotting time was monitored every hour for the first 4 hours until stable, and then every 4-8 hours for the rest of the protocol. Continuous heparin was infused to maintain an activated clotting time of 200-220 s.

On day 3, the patient experienced a mild seizure of the face which was controlled with valproic acid. At that time a corticosteroid was administered to block potential swelling.

Echocardiography demonstrated good ventricular function recovery at hour 54, after which the ECMO weaning process started. The ECMO circuit was removed at hour 81 without complications.

\section{OUTCOME AND FOLLOW-UP}

The time course of the patient's recovery was faster than expected. The patient's consciousness level improved to E3M5 on day 4 and to E4M6 on day 5. The patient was extubated on day 8 without obvious motor neurological signs except for short term memory loss. Brain CT and MRI studies 1 week after the episode demonstrated several minimal infarcts without significant symptoms. On day 9, the patient was diagnosed with Brugada syndrome, and on day 11 was treated by implantation of a cardioverter defibrillator. The patient was discharged without significant neurological deficits (Cerebral Performance Categories Scale 1) 32 days after the episode. The patient returned to his professional work as a urologist 2 months later.

\section{DISCUSSION}

This is the first case presentation of CSDH for refractory out-of-hospital cardiac arrest in a patient. The long no flow (at least $8 \mathrm{~min}$ ) and low flow $(44 \mathrm{~min})$ period before ECMO initiation was expected to hinder the recovery of the neurological insult, and we thought recovery might take more than 2-3 weeks.
The cerebral temperature applied was much lower than that previously obtainable by systemic means. Recovery from the neurological insult was more rapid than expected.

Several initial observations about implementation of the CSDH protocol in this case include: (a) a difference of $5-6^{\circ} \mathrm{C}$ between the core (bladder) and ipsilateral nasal temperatures was achieved and sustained; (b) left and right nasal probes were within $\sim 1.5^{\circ} \mathrm{C}$; (c) within 2 hours from the start of $\mathrm{CSDH}$, cerebral temperature had dropped below $30^{\circ} \mathrm{C}$; (d) the protocol demonstrated rapid achievement of the cerebral target and a 12 hour stable hold of core normothermia and the target cerebral temperature; and (e) the same system provided adequate controlled rewarming.

This case demonstrates that implementing a CSDH protocol is feasible. We do not believe or assert that the case demonstrates efficacy or clinical value, even though the specific outcome was favorable. Evaluation of the efficacy of the CSDH protocol and choice of target temperatures will require larger studies.

Contributors C-HW: writing and designing the system. Y-TL and H-WC: patient care. Y-CW and J-JH: catheter intervention. JRG: design. YSC: writing, design of the system, and intervention.

Competing interests Chih-Hsien Wang, Yu-Ting Lin, Mao Ting, Heng-Wen Chou, Yi-Chih Wang, Juey-Jen Hwang, Yih-Sharng Chen: none. John R. Gilbert is both the

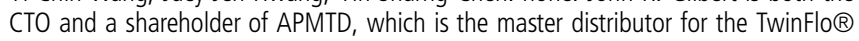
Device in Taiwan.

Patient consent Obtained.

Ethics approval The institutional review board approved the study (series No 2016-03049 BIPA).

Provenance and peer review Not commissioned; externally peer reviewed.

Data sharing statement The authors agree to share unpublished data if requested.

Open Access This is an Open Access article distributed in accordance with the Creative Commons Attribution Non Commercial (CC BY-NC 4.0) license, which permits others to distribute, remix, adapt, build upon this work non-commercially, 
and license their derivative works on different terms, provided the original work is properly cited and the use is non-commercial. See: http://creativecommons.org/ licenses/by-nc/4.0/

\section{REFERENCES}

1 Chen YS, Chao A, Yu HY, et al. Analysis and results of prolonged resuscitation in cardiac arrest patients rescued by extracorporeal membrane oxygenation. J Am Coll Cardiol 2003;41:197-203.

2 Chen YS, Yu HY, Huang SC, et al. Extracorporeal membrane oxygenation support can extend the duration of cardiopulmonary resuscitation. Crit Care Med 2008;36:2529-35.

3 Chen YS, Lin JW, Yu HY, et al. Cardiopulmonary resuscitation with assisted extracorporeal life-support versus conventional cardiopulmonary resuscitation in adults with in-hospital cardiac arrest: an observational study and propensity analysis. Lancet 2008:372:554-61.
4 Donnino MW, Andersen LW, Berg KM, et al. Temperature management after cardiac arrest. An advisory statement by the Advanced Life Support Task Force of the International Liaison Committee on Resuscitation and the American Heart Association Emergency Cardiovascular Care Committee and the Council on Cardiopulmonary, Critical Care, Perioperative and Resuscitation. Circulation 2015;132:2448-56.

5 Schwartz $A E$, Finck AD, Stone JG, et al. Delayed selective cerebral hypothermia decreases infarct volume after reperfused stroke in baboons. J Neurosurg Anesthesiol 2011;23:124-30.

6 Mattingly TK, Denning LM, Siroen KL, et al. Catheter based selective hypothermia reduces stroke volume during focal cerebral ischemia in swine. J Neurolnterventional Surg 2016;8:418-22.

7 Wang $\mathrm{CH}$, Chou NK, Becker LB, et al. Improved outcome of extracorporeal cardiopulmonary resuscitation for out-of-hospital cardiac arrest-a comparison with that for extracorporeal rescue for in-hospital cardiac arrest. Resuscitation 2014;85:1219-24.

Copyright 2017 BMJ Publishing Group. All rights reserved. For permission to reuse any of this content visit http://group.bmj.com/group/rights-licensing/permissions.

BMJ Case Report Fellows may re-use this article for personal use and teaching without any further permission.

Become a Fellow of BMJ Case Reports today and you can:

- Submit as many cases as you like

- Enjoy fast sympathetic peer review and rapid publication of accepted articles

- Access all the published articles

- Re-use any of the published material for personal use and teaching without further permission

For information on Institutional Fellowships contact consortiasales@bmjgroup.com

Visit casereports.bmj.com for more articles like this and to become a Fellow 